\title{
Effect of Abstraction on Permeability and Hydraulic Gradient in a Simulated Unconfined Aquifer Using Sand Tank Model
}

\author{
MD. SERAZUL ISLAM* \\ School of Agriculture and Rural Development, Bangladesh Open University, Gazipur, Bangladesh
}

Received 10 March 2006; received in revised form 04 June 2006; accepted 22 June 2006

\begin{abstract}
An experiment was carried out at the Hydraulic Laboratory of the Department of Irrigation and Water Management (IWM), Bangladesh Agricultural University (BAU), Mymensingh during the period from June to October 2003 to observe the effect of abstraction on permeability and hydraulic gradient in a simulated unconfined aquifer using sand tank model. In this study discharge was measured by volumetric method and coefficient of permeability $(K)$ was calculated using Darcy's law. For this experiment sand having particle size from 0.006 to $2.0 \mathrm{~mm}$ were used. Water elevation of different piezometers was recorded for five different discharge rates such as 0.040, 0.0396, 0.035, 0.0322 and 0.03118 litre per second for layered stratum $(\mathrm{Cu}=1.76)$. The average values of coefficient of permeability and hydraulic gradient were $5.00 \mathrm{~mm} / \mathrm{s}$ and $0.1575 \mathrm{~m} / \mathrm{m}$, respectively. For homogeneous formation ( $\mathrm{Cu}=1.5)$, the discharges were $0.03675,0.03603,0.0355,0.03539$ and 0.03318 litre per second, and the calculated average values of coefficient of permeability and hydraulic gradient were $6.276 \mathrm{~mm} / \mathrm{s}$ and $0.1148 \mathrm{~m} / \mathrm{m}$, respectively. Hydraulic gradient for layered stratum was found higher than that of homogeneous formation. Very good linear relationship was found between water elevations and piezometric distances for both layered and homogeneous formations. The correlation coefficient ( $r$ ) between water elevations and piezometric distances for higher and lower discharges in layered stratum were found to be 0.964 and 0.993 also for homogeneous formations this values were 0.972 and 0.987 , respectively.
\end{abstract}

Key words: Discharge, hydraulic gradient, coefficient of permeability, groundwater flow model.

\section{INTRODUCTION}

Water is vital for mankind and modern civilization. Agriculture is the greatest user of water compared to other sectors. Of total global water resources about 97.2 percent is saline water and 2.8 percent is fresh water. Out of the available fresh water about 0.6 percent is groundwater and only 0.05 percent is surface water. Hence the largest available source of fresh water lies underground (Raghunath, 1987). Groundwater exploitation and utilization have become important as the water use in agriculture is increasing day by day. The development of groundwater resources plays a major role in increasing agricultural production to meet food requirement of the country for ever increasing population. Presently about 46 percent of the total cultivable land is under irrigation out of which about 74 percent is using groundwater (NMIDP, 2001). Groundwater is

* Corresponding author: Lecturer, SARD, BOU. E-mail: serazsard4@yahoo.com

(C) 2006, School of Agriculture and Rural Development, Bangladesh Open University. All rights reserved. 
the source of potable water supplied for about 95 percent of the population. In 1991, total groundwater utilization throughout the country was estimated to be about 10,600 million cubic meters (MPO, 1991). At present, the intensive exploitation of groundwater for irrigation has progressively been lowering the water table, which causes alarming situation of the renewable groundwater resource in many areas within the country (Debnath, 2000). Groundwater is essentially a hidden resource; studies of groundwater under both natural and artificial boundary conditions have employed modeling techniques. A sand tank model is a scale model of an aquifer with the boundaries scaled down. Most of the tubewells have been installed without knowing details of hydrogeologic characteristics of the aquifers. As a result, large numbers of DTWs are facing problem now a days.

Hydraulic gradient of aquifer is important to know groundwater movement as well as to determine well spacing, well interference, cone of depression and well efficiency. Aquifer conditions, coefficient of permeability, storage coefficient and distance of pumping well etc., are affecting the hydraulic gradient. Hydraulic conductivity is an important parameter for water well design. The entrance velocity through well screen increases with increasing hydraulic conductivity of the aquifer material (Walton, 1962). With a view to this, a laboratory based model study was undertaken and attempt was made to determine the impact of abstraction on coefficient of permeability and hydraulic gradient in a simulated unconfined aquifer.

\section{MATERIALS AND METHODS}

\section{Description of the equipment}

A Groundwater/well Abstraction Rig as shown in Fig. 1 (available in the department of IWM, BAU) was used for the experiment. The equipment consists of a sand tank manufactured from glassreinforced plastic and mounted on a mild steel frame. Four adjustable feet permit leveling of the equipment. Two independent water inlet ports are situated at each end of the tank; each port has a separate flow control valve allowing a fixed level inside the tank to be determined. Water can be fed to both ports simultaneously or separately to one port, whilst using the other port as a drain. A set of quick release connectors allows a rapid conversion from one configuration to another. Two wells with control taps in the base of the tank allow studies of abstraction. Nineteen tapings in the base of the tank arranged in a cruciform configuration are connected to a multi-tube manometer (Fig. 2), which is clipped to the side of the frame. The monometers are easily removable to assist in the priming of the manometers. The manometers can also be used to drain the sand tank fully. A sliding cursor on the manometer permits measurement of any level within the tank. A cylindrical ring is provided to create an excavation site for de-watering demonstrations.

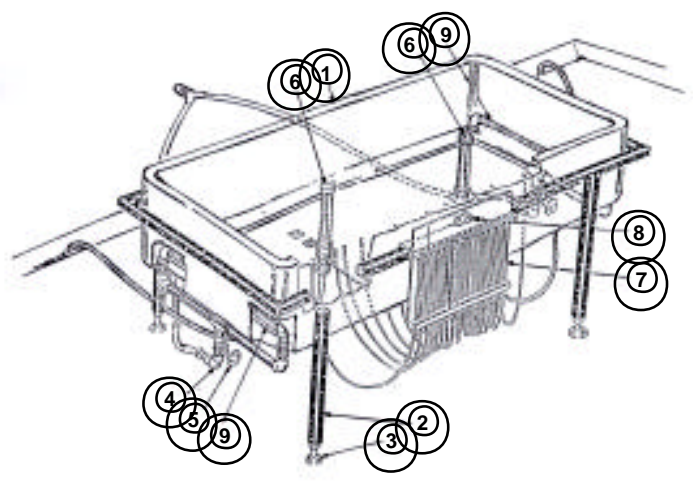

1. Sand tank;

2. Mild steel frame;

3. Adjustable feet;

4. Water inlet port;

5. Control Valve;

6. Well;

7. Multitube manometer

8. Level indicator;

9. Diffuser.

Fig. 1. Groundwater/Well Abstraction Rig 


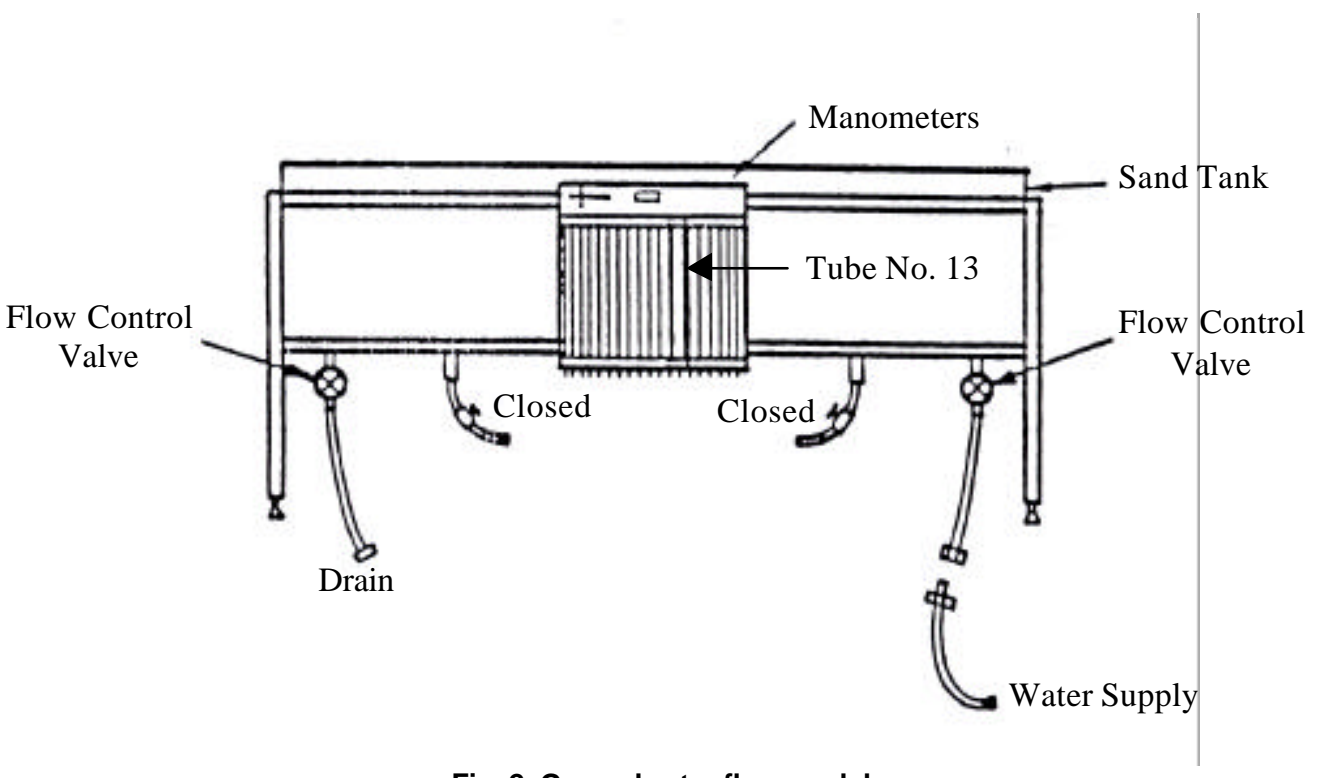

Fig. 2. Groundwater flow model

\section{Experimental set-up}

The equipment was initially commissioned with water without any sand. At first water inlet pipes were connected to " $Y$ " adapter and hydraulic bench for water supply. The tank was leveled using spirit level and adjustable feed. After leveling, flow control valve were fully opened. Water was supplied from hydraulic bench. It was confirmed that water enter the sand tank through two diffusers, water was drained through drainage valve. Control valves were closed and allowed to raise the water level up to $100 \mathrm{~mm}$, leakage was checked. The manometer board was removed and placed it in a bucket at a lower level than the sand tank. When all the tubes were running full with water, the manometer board was placed in its original position. These processes were done until all the water level in the manometers tube was same. Water supply was turned off and flow control valves were closed.

Sand was sieved by using standard set of sieves. One cubic meter of graded sand ranging in size from 0.06 to $2.0 \mathrm{~mm}$ was collected. Sand was washed thoroughly to remove silt and organic materials. Total depth of sand was $15 \mathrm{~cm}$ into the tank. The tank was filled with $2 \mathrm{~cm}$ of fine sand ( 0.06 to $0.2 \mathrm{~mm}$ ) as bottom layer, $3 \mathrm{~cm}$ of medium sand $(0.2$ to $0.6 \mathrm{~mm})$ as middle layer and $10 \mathrm{~cm}$ of coarse sand ( 0.6 to $2 \mathrm{~mm}$ ) as top layer for preparation of layered stratum. But for preparation of homogeneous formation all types of sand were mixed together and put into the sand tank.

Left-hand flow control valve was opened fully and right hand flow control valve was adjusted until a steady head was maintained. This was indicated by manometer tube No. 13 which is shown in Fig. 2 and 5 to 10 minutes were allowed to stabilize the condition. The manometer levels were recorded from linear scale. The flow rate was measured by volumetric method. Small discharge rates were computed accurately by recording the time with a stopwatch for every volume of water collected.

\section{Mathematical Expression}

The following equations were used in this study:

$$
\text { Discharge rate, } Q=\frac{\text { Volume of container }}{\text { Time }}\left(\mathrm{m}^{3} / \mathrm{s}\right)
$$

Velocity of flow i.e. volumetric flow rate per unit cross sectional area was determined from Darcy's Law (Todd, 1980) as: 
Again, Velocity,

$$
\begin{aligned}
V & =\frac{Q}{A} \quad \ldots . . \\
Q & =K A \frac{d h}{d l}
\end{aligned}
$$

From equation (2) and (3), $V=\frac{K A}{A} \frac{d h}{d l}=K \frac{d h}{d l}$

$$
\therefore \mathrm{K}=\frac{\mathrm{V}}{\mathrm{dh} / \mathrm{dl}}
$$

Where, $\mathrm{Q}=$ discharge rate, $\mathrm{K}=$ Coefficient of permeability, $\mathrm{A}=$ Cross sectional area of sand tank, $\frac{\mathrm{dh}}{\mathrm{dl}}=$ Hydraulic gradient and $\mathrm{V}=$ volumetric flow rate per unit cross sectional area.

Values of coefficient of permeability were calculated using equation (5).

\section{RESULTS AND DISCUSSION}

Sieve opening $(\mathrm{mm})$ and percent finer data were plotted on a semi-log paper in order to find the value of uniformity co-efficient and particle size of the individual samples from gradation curves. For layered stratum and homogeneous formation uniformity co-efficient of the sample were 1.76 and 1.50 , respectively, which are graphically shown in Figs. 3a and $3 \mathrm{~b}$. Calculated values of co-efficient of permeability $(\mathrm{K})$ and hydraulic gradient for layered stratum based on different discharges are shown in Table 1. Again, the values of co-efficient of permeability $(K)$ and hydraulic gradient for homogeneous formation for different discharges are presented in Table 2. From the experimental data an attempt was made to find the relationship between water levels in the piezometers and the distances of the corresponding piezometers. The relationship for layered stratum and homogeneous formation using higher and lower discharges are presented as hydraulic gradient curves in Figs. $4 a$ and $4 \mathrm{~b}$, respectively. In both cases the best-fitted lines of the water levels against piezometers distance curves were drawn by linear regression analysis. The regression line represented hydraulic gradient of formation. Correlation co-efficient $(r)$ between water elevations and piezometric distances for higher and lower discharges $(0.040$ and $0.0312 \mathrm{l} / \mathrm{s})$ in layered stratum were 0.964 and 0.993 , respectively. In homogeneous formation the corresponding values of correlation co-efficient were 0.972 and 0.987 , respectively.

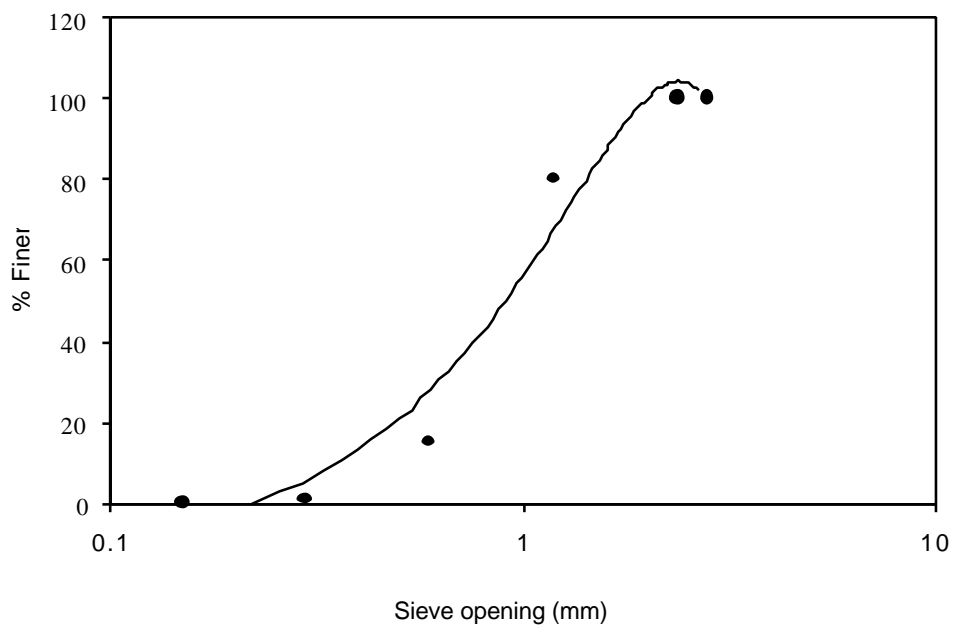

Fig. 3a. Gradation curve of sand for layered stratum ( $C U=1.78)$ 
Effect of abstraction on permeability and hydraulic gradient

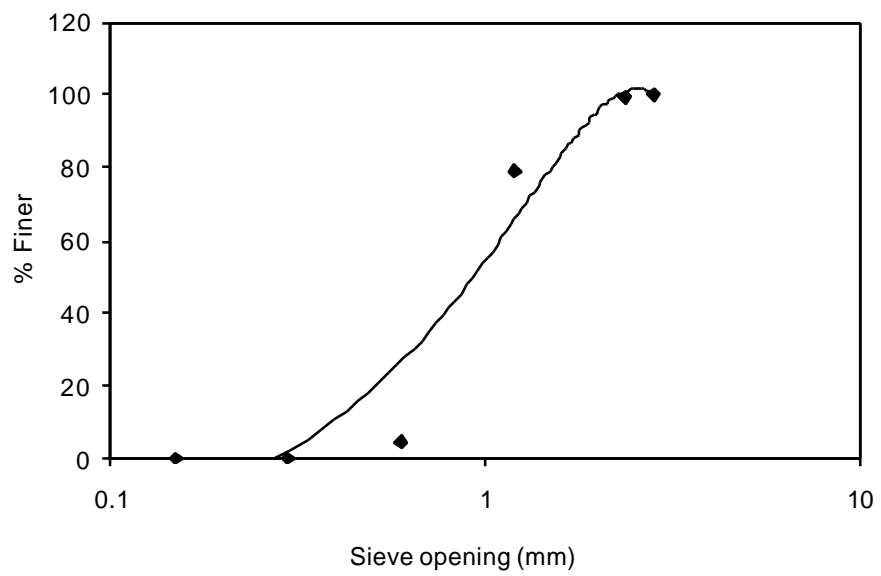

Fig. 3b. Gradation curve of sand for homogeneous formation (CU=1.50)

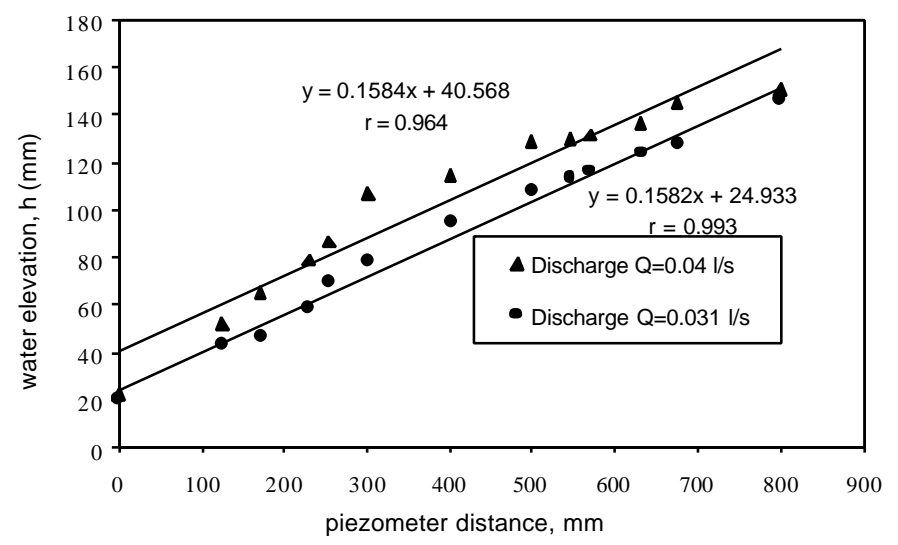

Fig. 4a. Relationship between water elevation and piezometer distance (Layered stratum) for various discharge values

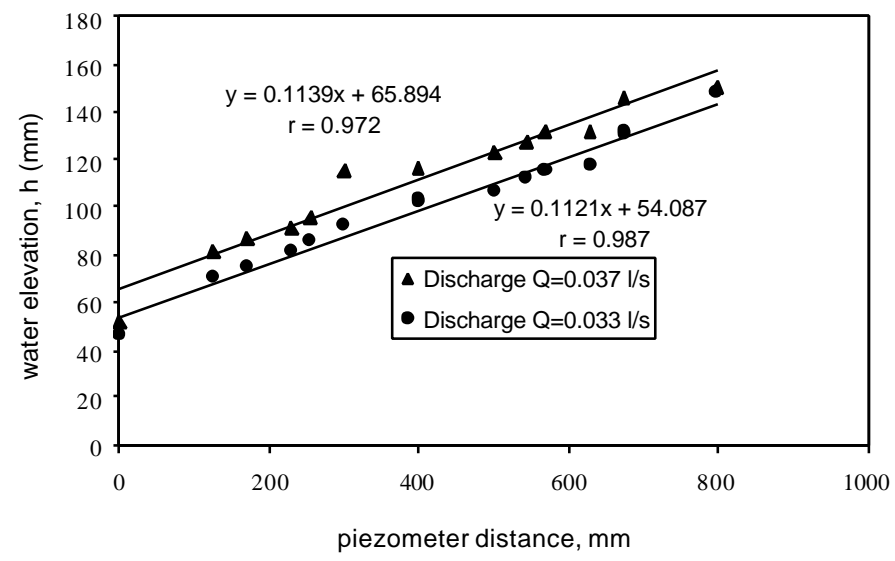

Fig. 4b. Relationship between water elevation and piezometer distance (Homogeneous formation) for various discharge values 
For layered stratum, the average value of co-efficient of permeability was $5.11 \mathrm{~mm} / \mathrm{s}$ and the value of hydraulic gradient was $0.1575 \mathrm{~m} / \mathrm{m}$ whereas for homogeneous stratum, the average value was $6.276 \mathrm{~mm} / \mathrm{s}$ and $0.1148 \mathrm{~m} / \mathrm{m}$, respectively. The typical values of co-efficient of permeability as determined in laboratory for coarse sand usually ranges from $2.10 \mathrm{~mm} / \mathrm{s}$ to $3.09 \mathrm{~mm} / \mathrm{s}$ at $60^{\circ} \mathrm{F}$ (Johnson, 1963). The value of co-efficient of permeability in this experiment was found greater than the average values. It might be due to the fact that when unconsolidated samples are disturbed and repacked, porosities, packing and grain orientations are markedly changed.

Table 1. Calculated value of Co-efficient of permeability and Hydraulic gradient for Layered stratum using different discharge conditions

\begin{tabular}{|c|c|c|c|c|c|c|c|}
\hline $\begin{array}{l}\text { Obs. } \\
\text { No. }\end{array}$ & $\begin{array}{c}\text { Discharge } \\
Q \\
(\mathrm{I} / \mathrm{s}) \\
\end{array}$ & $\begin{array}{c}\text { Area } \\
\mathrm{A} \\
\left(\mathrm{cm}^{2}\right) \\
\end{array}$ & $\begin{array}{c}\text { Velocity } \\
\mathrm{V} \\
(\mathrm{cm} / \mathrm{s}) \\
\end{array}$ & $\begin{array}{c}\text { Hydraulic } \\
\text { gradient } \\
\text { I }\end{array}$ & $\begin{array}{c}\text { Permeability } \\
\mathrm{K} \\
(\mathrm{mm} / \mathrm{s}) \\
\end{array}$ & $\begin{array}{c}\text { Average } \\
\text { hydraulic } \\
\text { gradient } \\
\end{array}$ & $\begin{array}{c}\text { Average } \\
\text { permeability } \\
\mathrm{K}(\mathrm{mm} / \mathrm{s}) \\
\end{array}$ \\
\hline 1 & 0.0400 & 470.4 & 0.085 & 0.1584 & 5.37 & & \\
\hline 2 & 0.0396 & 437.7 & 0.091 & 0.1618 & 5.59 & & \\
\hline 3 & 0.0350 & 441.0 & 0.079 & 0.1526 & 5.20 & 0.1575 & 5.11 \\
\hline 4 & 0.0322 & 431.2 & 0.075 & 0.1566 & 4.77 & & \\
\hline 5 & 0.0312 & 426.3 & 0.073 & 0.1582 & 4.62 & & \\
\hline
\end{tabular}

Table 2. Calculated value of Co-efficient of permeability and Hydraulic gradient for Homogeneous formation using different discharge conditions

\begin{tabular}{cccccccc}
\hline $\begin{array}{c}\text { Obs. } \\
\text { No. }\end{array}$ & $\begin{array}{c}\text { Discharge } \\
\mathrm{Q} \\
(\mathrm{l})\end{array}$ & $\begin{array}{c}\text { Area } \\
\mathrm{A} \\
\left(\mathrm{cm}^{2}\right)\end{array}$ & $\begin{array}{c}\text { Velocity } \\
\mathrm{V} \\
(\mathrm{cm} / \mathrm{s})\end{array}$ & $\begin{array}{c}\text { Hydraulic } \\
\text { gradient } \\
\mathrm{I}\end{array}$ & $\begin{array}{c}\text { Permeability } \\
\mathrm{K} \\
(\mathrm{mm} / \mathrm{s})\end{array}$ & $\begin{array}{c}\text { Average } \\
\text { hydraulic } \\
\text { gradient }\end{array}$ & $\begin{array}{c}\text { Average } \\
\text { permeability } \\
\mathrm{K}(\mathrm{mm} / \mathrm{s})\end{array}$ \\
\hline \hline 1 & 0.03675 & 519.4 & 0.0707 & 0.1139 & 6.21 & & \\
2 & 0.03603 & 499.8 & 0.0721 & 0.1138 & 6.33 & & \\
3 & 0.03550 & 473.7 & 0.0749 & 0.1139 & 6.57 & 0.1148 & 6.276 \\
4 & 0.03539 & 476.9 & 0.0744 & 0.1201 & 6.17 & & \\
5 & 0.03318 & 485.1 & 0.0684 & 0.1121 & 6.10 & & \\
\hline
\end{tabular}

Hydraulic gradient for layered stratum was found higher than that of homogeneous formation. It might be due to higher head loss in laminated formation, which consists of alternating fine, medium and coarse layers. Highest permeability was observed in homogeneous formation than that of layered stratum. It indicates that the homogeneous formation can serve as a good aquifer. A good linear relationship was found between water elevations and piezometers distances for both layered stratum and homogeneous formation.

\section{LITERATURE CITED}

Debnath, D. C. 2000. Aquifer Properties and Tubewell Performance in Mymensingh Sadar Upazilla. Unpublished [MS Thesis], Department of Irrigation Water Management, Bangladesh Agricultural University, Mymensingh. pp. 1-15.

Johnson, E. E. 1963. Groundwater and Wells. 1st Edn., Edward E. Johnson Inc. St. Paul, Minnesota, USA. pp. 48-52

MPO. 1991. National Water Plan. Final Draft Report, Vol. 11, Ministry of Water Development Board and Flood Control, Government of Bangladesh. pp. 50-75.

NMIDP. 2001. National Minor Irrigation Census 1999/2000. National Minor Irrigation Development Project, Ministry of Agriculture, Govt. of Bangladesh. pp. 13-16.

Raghunath, H. M. 1987. Groundwater. 2nd Edn., New Argil. International Pub., New Delhi. pp. 1-2.

Todd, D. K. 1980. Groundwater Hydrology. 2nd Edn., John Willy and Sons, New York. pp. 64-78

Walton, W. C. 1962. Selected Analytical Methods for Well and Aquifer Elevation. Illinois State Water Survo Bull. pp. $49-81$. 